\title{
Effects of crowding and photoperiod on wing morph and egg production in Eobiana engelhardti subtropica (Orthoptera: Tettigoniidae) ${ }^{\dagger}$
}

\author{
Morio HigaKI ${ }^{*}$, and Yoshikazu Ando \\ Laboratory of Entomology, Faculty of Agriculture and Life Science, Hirosaki University; Hirosaki 036-8561, Japan
}

(Received 30 October 2002; Accepted 31 March 2003)

\begin{abstract}
Eobiana engelhardti subtropica (formerly Metrioptera hime) is wing-dimorphic. The long-winged (LW) morph was clearly induced by crowding during the nymphal stages. Short-winged (SW) females produced eggs more intensively in an earlier period than did LW females. This difference in egg production between the two wing morphs seems to be associated with different patterns of increase in body weight after adult emergence. The body weight of SW females rapidly increased and reached its peak at about the time when oviposition started. On the other hand, the increase in body weight of LW females was slow, although it continued even after the start of oviposition. These findings suggest that the SW morph is adapted to sedentary life and rapid reproduction and that the LW morph tends to migrate before or during reproduction. However, in both the morphs, reproductive traits (pre-oviposition period, egg-laying period, number of eggs laid, and longevity) were to some extent flexible and could be modified by photoperiodic conditions.
\end{abstract}

Key words: Tettigoniidae; Eobiana engelhardti subtropica; wing dimorphism; egg production; photoperiod

\section{INTRODUCTION}

Wing dimorphism is common in various groups of insects (Harrison, 1980; Roff, 1986; Fujisaki, 1994). In most cases, two morphs represent classes of individuals with different wing lengths. Shortwinged (SW) and long-winged (LW) morphs differ from each other in various anatomical, physiological, and life-history traits. In general, the SW morph is adapted to prompt reproduction in a suitable habitat, whereas the LW morph is adapted to dispersal activity and later reproduction. Such understanding of wing dimorphism is based on the extensive study of rather limited groups of species, most of which are usually important agricultural pests or are suitable for rearing successive generations. As wing dimorphism has been considered a common feature which evolved independently in many orders of insects (Fujisaki, 1994), accumulation of studies on a wide range of species is necessary to formulate a basic understanding of dispersal dimorphisms in insects.

In Orthoptera involving many agricultural pests, wing dimorphism has been studied in detail only in Gryllidae (Masaki and Walker, 1987). Little has been reported about wing dimorphism in other families of this order. During our study of the life cycles of tettigoniids, we found that wing dimorphism occurs in Eobiana engelhardti subtropica, Conocephalus japonicus, and Metrioptera bonneti. Thus, wing dimorphism appears to be common in Tettigoniidae. However, the biological significance of wing dimorphism in this group of insects has been reported only by Ando and Hartley (1982). This scarcity of information is partly due to the difficulties associated with rearing katydids (Hartley and Dean, 1974).

E. e. subtropica is widely distributed in the Japanese archipelago (Storozhenko and Yamasaki, 1993). It lives mostly in moist meadows and has a univoltine life cycle, overwintering at the mature embryonic stage (Higaki and Ando, 1999, 2002). Both sexes are usually SW morph, with tegmina and hind wings not reaching the tip of the abdomen. However, in the LW morph, the tegmina and hind wings extend beyond the abdominal tip. This morph is occasionally found in the field (Kobayashi, 1981). In the present study, we examined the effect of crowding on wing-morph determination and compared the characteristics of egg

\footnotetext{
* To whom correspondence should be addressed at: E-mail: scarabee@affrc.go.jp

$\dagger$ Metrioptera hime Furukawa has been used in previous papers.

\$ Present address: Laboratory of Entomology, Department of Plant Protection, National Institute of Fruit Tree Science; Tsukuba 305-8605, Japan
} 
production between SW and LW morphs under short and long photoperiodic conditions in $E$. $e$. subtropica. The ecological significance of wing dimorphism and environmental modification of reproductive traits of both morphs are discussed.

\section{MATERIALS AND METHODS}

Insects. Adults and nymphs of E. e. subtropica were collected in the lowlands around Hirosaki $\left(40.6^{\circ} \mathrm{N}\right)$ in 1992 and 1993. Adults were reared in a netted steel cage $(30 \times 30 \times 30 \mathrm{~cm})$ in the laboratory. Pellets of insect feed (Oriental Yeast Co., Tokyo), wheat germ (Nisshin Seifun Co., Tokyo), and pupae of Mamestra brassicae or larvae of Tenebrio molitor were provided as food. A bundle of Poa annua was inserted into a water flask. Several such flasks were put in each cage for oviposition and as additional food, and these were renewed every 2-4 days. Eggs for the experiments of wingmorph determination were obtained from these adults. Field-collected nymphs were reared in cages in a greenhouse from May to July in 1992. The rearing cages were made according to Hartley and Dean (1974) with slight modification. The cages were made of green nylon gauze and wooden frames $(55 \times 36 \times 47 \mathrm{~cm})$ and provided with a leg at one corner. These cages were designed to fit on to plastic trays $(55 \times 36 \times 10 \mathrm{~cm})$. The trays were planted with assorted plants (Poa аппиа, Bromus catharticus, Plantago asiatica, Rumex japonicus, Artemisia montana, Trifolium repens, etc.) as food. The other food conditions were the same as in the adult rearing. A similar rearing method was used in 1993.

Effect of crowding on wing-morph determination. Hatchlings were reared at densities of 1, 2, and 4 in a glass cylinder $(18 \mathrm{~cm}$ high $\times 12 \mathrm{~cm}$ in diameter) in which Poa annua was planted; hatchlings were kept under LD 14:10 h (14 h light: $10 \mathrm{~h}$ dark) at $25^{\circ} \mathrm{C}$. The foods described above were provided. When the insects molted to the penultimate stadium, they were reared individually to prevent cannibalism. Body size and wing length measurements were compared between LW and SW morphs of each sex by one-way ANOVA.

Reproduction and longevity of adults. Adults of the SW and LW morphs that emerged in the greenhouse in 1992 were used. Upon adult emergence, females and males were paired in glass cylinders under LD $16: 8 \mathrm{~h}$ or LD $12: 12 \mathrm{~h}$ at $26^{\circ} \mathrm{C}$. Natural daylength was about $16 \mathrm{~h}$ at the time of adult emergence in Hirosaki. Other conditions were the same as those used for the mass adult rearing. The number of eggs laid was counted every other day. The date of death was recorded for each individual. Data of reproductive traits were Box-Cox transformed to correct effectively for heterogeneity and improve normality and were analyzed by two-way ANOVA with the two factors of wing morph and day length. All statistical analyses were conducted using JMP version 5.0.1 J (SAS Institute Inc., 2002).

Change in adult body weight. Female adults of both wing morphs that emerged in a greenhouse in 1993 were paired with males in a glass cylinder under LD $14: 10 \mathrm{~h}$ at $25^{\circ} \mathrm{C}$. Females were weighed individually by an electric balance (AE100, Mettler-Toledo AG, Greifensee, Switzerland) every other day after adult emergence.

\section{RESULTS}

Effect of crowding on wing-morph determination

Although survival rate was not significantly different among the three groups reared at different densities $\left(\chi^{2}\right.$-test; $\chi^{2}=2.511$, d.f. $=2$ and $p=0.285$; Table 1), the percentage of LW morph was significantly different among the three groups $\left(\chi^{2}\right.$-test; $\chi^{2}=29.185$, d.f. $=2$ and $\left.p<0.001\right)$. Thus, LW morphs were clearly induced by crowding.

The tegmina of LW morphs were almost twice as long as those of SW morphs in both the sexes (Table 2). Differences between LW and SW morphs in body size indicated by head width and hind femur length were significant in females but not in males. In addition, SW females were significantly larger in ovipositor length than LW females.

\section{Pre-oviposition period}

Pre-oviposition periods were significantly differ-

Table 1. The effect of rearing density on the frequency of LW individuals in E. e. subtropica

\begin{tabular}{cccc}
\hline $\begin{array}{c}\text { Initial } \\
\text { density }\end{array}$ & $\begin{array}{c}\text { Initial } \\
\text { sample size }\end{array}$ & \% survival & $\begin{array}{c}\text { \% LW } \\
\text { morph }\end{array}$ \\
\hline 1 & 53 & 49.1 & 0 \\
2 & 22 & 68.2 & 60.0 \\
4 & 32 & 59.4 & 73.7 \\
\hline
\end{tabular}


Table 2. Body size and wing length measurements of the SW and LW morphs of E. e. subtropica

\begin{tabular}{ccccccc}
\hline \multirow{2}{*}{ Sex } & Wing morph & $N$ & Head width & Tegminal wing length & Hind femur length & Ovipositor length \\
\hline \multirow{2}{*}{ Male } & SW & 13 & $4.30 \pm 0.02$ & $14.23 \pm 0.28$ & $19.70 \pm 0.16$ \\
& LW & 18 & $4.25 \pm 0.03$ & $27.05 \pm 0.20$ & $19.57 \pm 0.13$ \\
& & $F$-value & 2.35 & $1,459.68$ & 0.41 & 0.529 \\
\multirow{2}{*}{ Female } & SW & 13 & $4.69 \pm 0.03$ & $<0.001$ & $21.73 \pm 0.14$ & $9.32 \pm 0.07$ \\
& LW & 36 & $4.51 \pm 0.02$ & $13.23 \pm 0.25$ & $21.06 \pm 0.10$ & 35.36 \\
& & $F$-value & 23.34 & $27.73 \pm 0.17$ & 13.11 & $<0.001$ \\
\hline
\end{tabular}

${ }^{\mathrm{a}} \mathrm{mm}$, mean $\pm \mathrm{SE}$.

Table 3. Reproductive traits of SW and LW females of E. e. subtropica under long-day and short-day photoperiodic conditions at $26^{\circ} \mathrm{C}^{\mathrm{a}, \mathrm{b}}$

\begin{tabular}{llcc}
\hline & & \multicolumn{2}{c}{ Day length } \\
\cline { 3 - 4 } & & LD $12: 12 \mathrm{~h}$ & LD $16: 8 \mathrm{~h}$ \\
\hline \multirow{2}{*}{ Pre-oviposition period in days } & SW & $11.2 \pm 0.8(9-18 ; 12)$ & $13.8 \pm 1.0(9-18 ; 10)$ \\
& LW & $18.8 \pm 1.5(14-26 ; 9)$ & $24.8 \pm 3.1(15-37 ; 8)$ \\
No. of eggs laid & SW & $281.6 \pm 42.4(81-531 ; 12)$ & $398.4 \pm 48.6(133-630 ; 10)$ \\
& LW & $201.0 \pm 37.1(29-377 ; 9)$ & $324.6 \pm 41.6(166-500 ; 8)$ \\
Egg-laying period in days & SW & $38.7 \pm 4.6(18-70 ; 12)$ & $58.0 \pm 4.5(40-84 ; 10)$ \\
Longevity in days & LW & $44.2 \pm 6.3(24-76 ; 9)$ & $75.0 \pm 5.1(54-96 ; 8)$ \\
& SW & $56.3 \pm 4.7(32-85 ; 12)$ & $76.0 \pm 3.8(60-97 ; 10)$ \\
& LW & $65.0 \pm 5.5(43-89 ; 9)$ & $107.3 \pm 5.4(80-123 ; 8)$
\end{tabular}

a Adults emerged in the greenhouse were transferred to different photoperiodic conditions on the day of emergence.

${ }^{\mathrm{b}}$ Mean \pm SE (range; $\left.n\right)$.

ent (Table 3), depending on the wing morph $(F=43.79$, d.f. $=1,35$ and $p<0.001)$ and day length $(F=7.47$, d.f. $=1,35$ and $p=0.010)$. LW females had a more variable pre-oviposition period ranging from 15 to 37 days under LD $16: 8 \mathrm{~h}$ than under LD $12: 12 \mathrm{~h}$. These findings suggest that photoperiodic conditions modified the timing of reproduction to some degree in both the LW and SW females.

\section{Change in adult body weight}

The body weight of SW females rapidly increased and reached a maximum about 10 days after adult emergence (Fig. 1). In LW females, the body weight increased by about $30 \%$ until the 2 nd day in a manner similar to that of SW females. However, body weight decreased thereafter, and then gradually increased again after the 6th day. The increase curve reached a plateau after 40 days. The SW females attained their maximum body

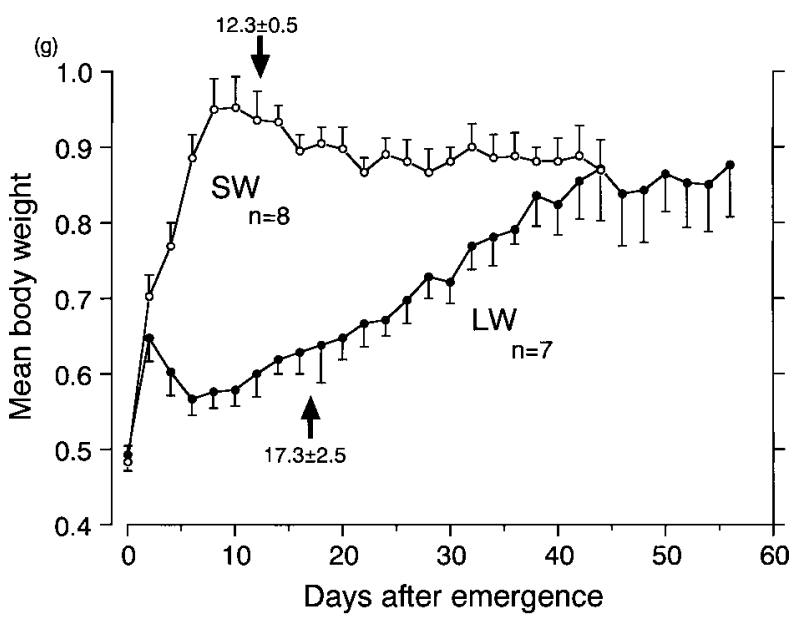

Fig. 1. Changes in mean body weight of SW and LW females of E. e. subtropica transferred to $\operatorname{LD} 14: 10 \mathrm{~h}$ at $25^{\circ} \mathrm{C}$ from a greenhouse on the day of adult emergence. SW and LW females that survived longer than 30 days and 40 days, respectively, were used. Vertical bars indicate one side of SE. Arrows indicate mean pre-oviposition period of each wing morph used for weighing. 


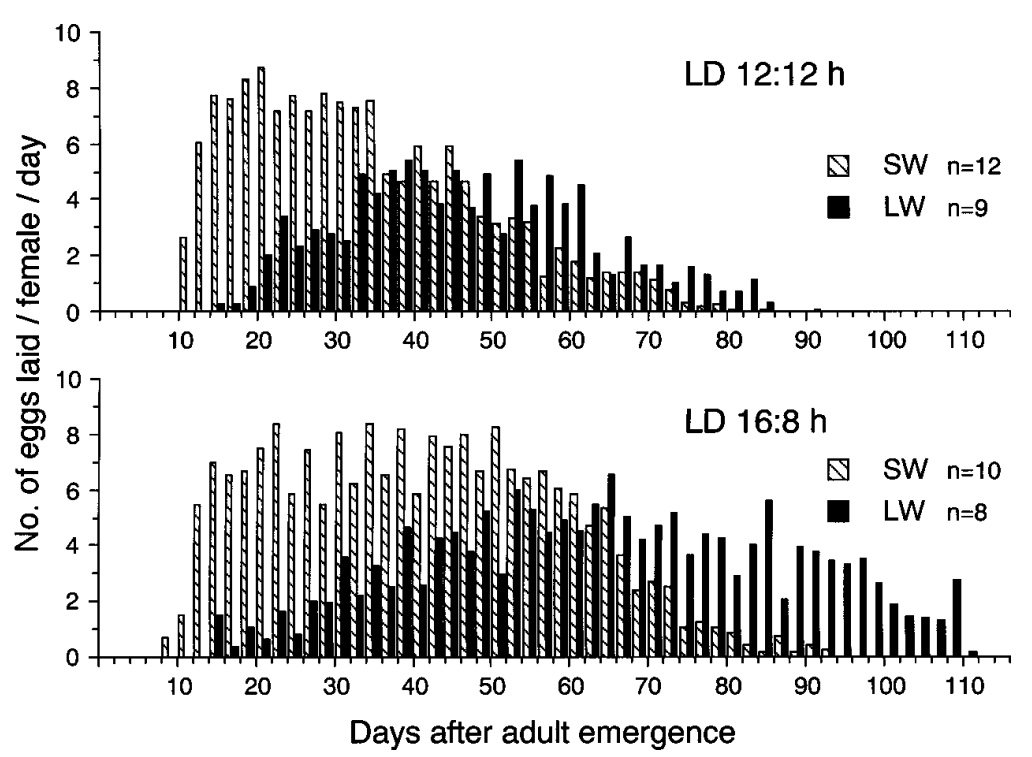

Fig. 2. Egg production of SW and LW females of E. e. subtropica transferred to short or long photoperiodic condition from the greenhouse on the day of adult emergence.

weight before they started oviposition, whereas the LW females continued to gain weight even after they started to lay eggs. The difference between the two morphs with regard to the peak time of body weight (about 34 days) was much larger than with regard to the pre-oviposition period (about 4 days).

\section{Egg production}

The two morphs showed different patterns of oviposition (Fig. 2). SW females reached peak egg production earlier than LW females did under both LD 12:12 h and LD 16:8 h. Egg-laying period was significantly affected by day length $(F=23.26$, d.f. $=1,35$ and $p<0.001$; Table 3 ), but not by wing morph $(F=4.10$, d.f. $=1,35$ and $p=0.051)$. LW females laid eggs for a markedly longer period under LD $16: 8 \mathrm{~h}$, and some of them laid eggs even 100 days after adult emergence.

Only the day length was responsible for the difference in the number of eggs laid $(F=7.74$, d.f. $=1,35$ and $p=0.009)$. Under both short and long photoperiods, SW females laid a larger number of eggs than did LW females, but wing morph was not a significant factor in egg production $(F=2.80$, d.f. $=1,35$ and $p=0.103)$.

\section{Adult longevity}

Life time differed significantly according to wing morph $(F=16.56$, d.f. $=1,35$ and $p<0.001$; Table 3$)$ and day length $(F=39.85$, d.f. $=1,35$ and $p<0.001)$. The interaction of these two factors was also significant $(F=5.30$, d.f. $=1,35$ and $p=0.027)$, and the difference between the two morphs was dramatically longer under conditions of LD $16: 8 \mathrm{~h}$ than under LD 12:12 h; more than half of the LW morphs survived over 100 days under LD 16:8 h.

\section{DISCUSSION}

E. e. subtropica produces LW individuals under high density conditions (Table 1), as has been demonstrated in many other wing-dimorphic insects (Harrison, 1980; Fujisaki, 1994). SW females produced eggs more intensively during an earlier period than did LW females (Fig. 2). This difference in early egg production appears to be related to different patterns of increase in body weight between the two morphs (Fig. 1). Ando and Hartley (1982) obtained similar results in a wing-dimorphic katydid, Conocephalus discolor. They suggested the possibility that early light loading facilitates the flight of LW females. Thus, in E. e. subtropica and $C$. discolor, the LW morph is adapted for dispersal with slow and long reproduction, whereas the SW morph is adapted for sedentary life and rapid reproduction.

Occurrence of LW individuals is common among insects living in temporary environments (Vepsäläinen, 1978; Harrison, 1980; Denno et al., 1991). Many species of temperate tettigoniids are 
adapted to grasslands representing an early stage of ecological succession. The insects may migrate to other grassy areas as habitat conditions become deteriorated with ecological succession. E. e. subtropica occurs commonly in rather moist grassy conditions. Such habitats exist discretely; they also tend to be unstable and disturbed by exploitation. Thus, wing dimorphism of E. e. subtropica may reflect an adaptation to habitat instability.

Vickery (1965) has reported that in Metrioptera roeseli, the LW morph might be a dispersal phase for extending its distributional areas in North America. We did not study the flying ability of the LW morph of E. e. subtropica, but we observed LW morphs flying in the field several times in midsummer. We have circumstantial evidence for their high flying ability. We found LW individuals of $E$. e. subtropica several times in bogs at high altitudes in the Hachimantai mountains $\left(40^{\circ} \mathrm{N}, 965 \mathrm{~m}\right)$; in the bogs, there is insufficient heat unit for this katydid to complete one generation per year (Higaki and Ando, unpublished). No SW individual was found there, despite frequent collecting efforts. We did not find larva of E. e. subtropica at altitudes higher than $600 \mathrm{~m}$ in 1992-1997. These observations suggest that only the LW morph of this katydid can disperse over a long distance.

We did demonstrate that egg production in both wing morphs was to some extent influenced by photoperiodic conditions in the adult stage, although we did not examine the effects of photoperiodic conditions on wing-morph determination as known in many wing-dimorphic species (Harrison, 1980; Masaki and Walker, 1987; Kisimoto, 1996). The egg-laying period and adult longevity were much longer under long-day condition than shortday condition (Table 3 ). Moreover, egg production was slightly accelerated and concentrated in an early stage by short-day condition (Fig. 2 and Table $3)$. Eggs of this katydid typically require a long time to reach the diapause stage (about 50 days at $20^{\circ} \mathrm{C}$ : Higaki and Ando, 2002). Therefore, the short-day acceleration of oviposition may enable eggs to reach the diapause stage before winter.

The present study showed that the SW morph is adapted to sedentary life and rapid reproduction and that the LW morph tends to migrate before or during reproduction, and the reproductive traits of both morphs can to some extent be modified by photoperiodic conditions.

\section{ACKNOWLEDGEMENTS}

We are deeply obliged to Sinzo Masaki for critically reading our early draft. We also thank Yasuyuki Shirota for continuous encouragement. Thanks are also due to Koichi Tani, Toshio Watanabe, Isao Kasai, Yoshio Kudo, and Kenji Yamamoto for looking after our insects while we were away.

This paper is contribution No. 141 from the Laboratory of Entomology, Faculty of Agriculture and Life Science, Hirosaki University.

\section{REFERENCES}

Ando, Y. and J. C. Hartley (1982) Occurrence and biology of a long-winged form of Conocephalus discolor. Entomol. Exp. Appl. 32: 238-241.

Denno, R. F., G. K. Roderick, K. L. Olmstead and H. G. Dobel (1991) Density-related migration in planthoppers (Homoptera: Delphacidae): The role of habitat persistence. Amer. Nat. 138: 1513-1541.

Fujisaki, K. (1994) Adaptive significance and evolution of dispersal polymorphisms in insects. Sci. Rep. Fac. Agr. Okayama Univ. 83: 113-132 (in Japanese with English summary)

Harrison, R. G. (1980) Dispersal polymorphism in insects. Annu. Rev. Ecol. Syst. 11: 95-118.

Hartley, J. C. and R. L. Dean (1974) Ephippiger cruciger as a laboratory insect (Orthoptera: Tettigoniidae). J. Nat. Hist. 8: 349-354.

Higaki, M. and Y. Ando (1999) Seasonal and altitudinal adaptations in three katydid species: Ecological significance of initial diapause. Entomol. Sci. 2: 1-11.

Higaki, M. and Y. Ando (2002) The effect of temperature on embryonic development and local adaptation in the life cycle of Eobiana engelhardti subtropica Bey-Bienko (Orthoptera: Tettigoniidae). Appl. Entomol. Zool. 37: 625-636

Kisimoto, R. (1996) Wing polymorphism in Planthoppers, Delphacidae: Its diversity and adaptive meanings. Plant Protect. 50: 255-260 (in Japanese).

Kobayashi, M. (1981) Grasshoppers, Crickets and Allied Insects in Nagano Pref. Akinomushinokai, Nagano. 264 pp. (in Japanese).

Masaki, S. and T. J. Walker (1987) Cricket life cycles. Evol. Biol. 21: 349-423.

Roff, D. A. (1986) The evolution of wing dimorphism in insects. Evolution 40: 1009-1020.

SAS Institute Inc. (2002) JMP User's Guide, Version 5. SAS Institute Inc., Cary, NC.

Storozhenko, S. and T. Yamasaki (1993) Review of Orthoptera of Eastern Palearctica: genus Eobiana Bey-Bienko (Orthoptera, Tettigoniidae, Platycleidini). Proc. Japan Soc. Syst. Zool. 49: 37-46.

Vepsäläinen, K. (1978) Wing dimorphism and diapause in Gerris: determination and adaptive significance. In Evolution of Insect Migration and Diapause (H. Dingle ed.). Springer-Verlag, New York, pp. 218-253.

Vickery, V. R. (1965) Factors governing the distribution and dispersal of the recently introduced grasshopper, Metrioptera roeseli (Hgb.) (Orthoptera: Ensifera). Ann. Soc. Ent. Quebec 10: 165-171. 